Title: Problem Definition and Information Provision by Federal Bureaucrats

Article type: Research Paper

Abstract :

Federal bureaucrats are important sources of information about policy problems. However, federal officials compete for this influence with organized interests plying their own problems and solutions. We attribute the differential agenda influence of the federal bureaucracy to efforts in Congress to construct workable problem definitions in a context of uncertainty about issues. From both behavioral and rational models of congressional decision making, we develop a theory of congressional search for information during problem definition under conditions of uncertainty. The theory presages the prominence of federal bureaucrats in this search, and especially under uncertainty. Using new data sets capturing the appearance of federal bureaucrats at congressional hearings, we find that the mobilization, prominence, and types of federal bureaucrats providing information is explainable in terms of congressional uncertainty about problem definitions.

Keywords: bureaucracy; Congress; public policy; problem definition Corresponding Author Samuel Workman

Corresponding Author's Institution: University of Oklahoma

$\begin{array}{ll}\text { Department: } & \text { Political Science } \\ \text { Address: } & 455 \text { W Lindsey } \\ \text { Email: } & \text { University of Oklahoma } \\ \text { Telephone Number: } & \text { samuel.workman@ou.edu } \\ \text { Country: } & \text { United States }\end{array}$

Order of Authors: Samuel Workman, JoBeth Shafran, Tracey Bark 


\title{
Problem Definition and Information Provision by Federal Bureaucrats
}

\begin{abstract}
Federal bureaucrats are important sources of information about policy problems. However, federal officials compete for this influence with organized interests plying their own problems and solutions. We attribute the differential agenda influence of the federal bureaucracy to efforts in Congress to construct workable problem definitions in a context of uncertainty about issues. From both behavioral and rational models of congressional decision making, we develop a theory of congressional search for information during problem definition under conditions of uncertainty. The theory presages the prominence of federal bureaucrats in this search, and especially under uncertainty. Using new data sets capturing the appearance of federal bureaucrats at congressional hearings, we find that the mobilization, prominence, and types of federal bureaucrats providing information is explainable in terms of congressional uncertainty about problem definitions.
\end{abstract}

Keywords: bureaucracy, Congress, public policy, problem definition

\section{Introduction}

Federal bureaucrats are important sources of information in the policy 3 process (Workman, Jones, and Jochim, 2009; May, Koski, and Stramp, 2014). 4 Scholars often depict bureaucrats' informational advantage as so powerful 5 that incentive and personnel systems are necessary to thwart bureaucratic 6 drift (Epstein and O'Halloran, 1999; Huber and Shipan, 2002; Lewis, 2008; Gailmard and Patty, 2013). In theories of public policy, bureaucracies ocs cupy a central position in policy subsystems (May et al., 2006) and make up part of the web of actors, including organized interests, generating information about public policy (Miller, 2004; May, Sapotichne, and Workman, 2006, 1 2009b). More recently, scholars have emphasized that the information gen12 erated by federal bureaucracies is shaped by, and influences, agenda setting 
and problem definitions at higher levels of government (Baumgartner and Jones, 2014; Workman, 2015). Federal bureaucracies provide information about policy problems in a pluralistic political context where they not only compete with organized interests, but also with other federal bureaucracies (Workman and Shafran, 2015).

The crafting of a working definition of a problem allows the construction of policies, or solution sets, for those problems (Simon, 1996; Jones, 2001). Problem definitions are important because they offer opportunities for bureaucracies and other actors to expand influence, but also offer fissures that allow actors to exploit deficiencies in the current definition, or understanding, of a problem and induce policy change (Dery, 1984). Given this, the ability to influence problem definitions implies the ability to steer policy change. Political scientists have not paid a great deal of attention to problem definitions in recent decades, despite their importance for policy change. Moreover, bureaucracies represent the institutionalization of particular definitions of policy problems (Workman, 2015, pp. 138-146), and considerable politics surround efforts to alter how bureaucracies define the problems they confront (May, Workman, and Jones, 2008). As such, the crafting of problem definitions, or working understandings, is a prime target of information generation and politicking of all types in the policy process, and especially in legislative policy making.

What drives attention to federal bureaucrats in the congressional search for information about policy problems? What types of bureaucrats are privileged in the construction of problem definitions? Theories about how federal bureaucracies operate in the policy process offer leverage in understanding how members of Congress might use bureaucrats in reaching an understanding of various policy problems. We argue that uncertainty guides decision making and choices about how to define a problems and search for information. We combine older insights from the fields of psychology and communication with those from public policy to derive some hypotheses about how best to understand the provision of information by bureaucrats and their prominence in policy debates. We assert that the central tenets of these theories have implications for the dynamics of mobilization in the hearing process and extend to how Congress searches for external information concerning policy problems.

We view bureaucratic participation as partly a consequence of the efforts of Congress to reduce uncertainty in decision making - especially concerning problem definition. These arguments are quite distinct from those charac- 
terizing standard theories of group mobilization and influence in the policy process. We test our basic assertions by examining the participation of federal bureaucrats in hearings on business and financial regulation over a significant period of time. While highlighting the importance of bureaucrats to congressional information gathering, our findings also hold more general implications for how we view the way in which Congress searches for information.

\section{Issue Dynamism and Boundary-Spanning Problems}

The sources of congressional uncertainty about problem definitions are twofold. The ability to prioritize policy issues and generate solutions presupposes that specific actors have jurisdiction over the problem and that the problem is defined in such a way as to allow solution generation. Congressional committees quite often engage in fierce competition in what King (1997) calls "turf wars" for jurisdictional supremacy and to control the contours of policy debate (Baumgartner, Jones, and MacLeod, 2000). That policy issues can be categorized easily is a more tenuous notion given the evolution and redefinition of policy issues (Jones and Baumgartner, 2005) and the interdependence of issues wrought by boundary-spanning policy problems (May, Sapotichne, and Workman, 2009a; May, Jochim, and Sapotichne, 2011; May and Koski, 2013).

Issues like climate change, homeland security, food security, and energy are examples of issues that span the boundary of existing issues, policies, and governing arrangements. These issues become ill-fit to existing structures for allocating attention (Sheingate, 2006). That is, they reside between or among substantive issues and functionally distinct governing arrangements. Their location in the agenda space sets in motion the struggle to define these problems. For instance, climate change defined in terms of environmental protection implies very different policies and considerations than does climate change understood in terms of its energy related dimensions. Such issues strain the existing set of governing arrangements and generate uncertainty about how to understand the policy problem. How might we expect the dynamics of issues to influence information search in legislatures?

Homeland security policy in the United States is an instructive case for beginning to understand how uncertainty about problem definitions might influence congressional information search. Standard distributional explanations of interest mobilization in this policy area would have predicted massive subsystem upheaval in the wake of the terrorist attacks of September 11, 
2001. All the elements for such a disruption were there. Massive resources, financial and otherwise, were available for analyzing, preventing, and mitigating future attacks. The federal bureaucracy was the target of great scorn, suggesting its value to Congress in information provision would have been down-graded. The creation of a "new" issue area and bureaucratic organizational upheaval might have suggested an opportunity for a restructuring of policy and flood of new participants into the policy process as Congress struggled to come to grips with the issue. This view of the potential of this disruption is heightened by the tremendous amount of money available for various programs protecting the homeland.

Yet, there was no "gold rush." Research documents, in the case of federal policy on the risk associated with homeland security, that Congress faced mounting uncertainty in this issue area as the new millennium began and that the stability of the issue areas that might have been affected was astounding - to the point of inertial. And further, this stability was marked not only in the case of organized interests, but most especially in terms of the set of federal bureaucracies tasked with policymaking on the issue areas affected (May, Sapotichne, and Workman, 2009a,b). Bureaucrats were central in defining the general directions of policy under extreme conditions of uncertainty. Further, the ultimate policy solution was an internal bureaucratic solution (May, Workman, and Jones, 2008; May and Workman, 2009). This discussion focuses on the importance of bureaucrats in policy making generally and processes of congressional search in particular. This instructive case sets the stage for a general logic of congressional search for information grounded in uncertainty about how to understand policy problems and craft definitions that would allow the generation of solutions.

\section{Problem Definition and the Bureaucracy}

Why are federal bureaucrats central to establishing working problem definitions, especially under conditions of uncertainty? From the vantage point of Congress, their competitors in the system of organized interests populating any given policy area faces market-like pressures on their survival as some groups fade away and others rise to prominence in the competition to represent latent interests. While the groups populating the interest system face competitive pressures for survival, they must also confront the ever-present internal tensions deriving from the politics of collective action that threaten to destroy or dissolve given organizations (Olson, 1965). These constitute 
market-like forces for interest representation and influence mobilization and information from the "supply" side.

Three characteristics of information are key for reduction of uncertainty in the political and policy calculus of legislators: accuracy, reliability, and consistency in supply. First, information must be factual or truthful in some sense, or at least close enough to allow the accurate weighting of the information. Second, information must be reliable. Legislators would like information that is not only "right" on average, but must also have low variance. Third, policymakers require a consistent supply of information to inform both policy and political calculations. Volatility in the supply of information destabilizes congressional policy making. These central characteristics of information supply highly recommended federal bureaucracies as primary suppliers of information in American politics generally, and especially under the uncertainty wrought by issue redefinition and boundary-spanning problems.

Bureaucracies generally have longer shelf-lives than the vast majority of groups populating the interest system. This is due to the nature of competition these groups face in the "interest marketplace", and is true not only in terms of the overall supply of groups, but also in the makeup of the population. Even as organized interests proliferate, the life-span of any given group is necessarily short in comparison to federal agencies. The nature of competition in the interest system compromises the consistency and reliability of information from these groups within any given issue area. Federal agencies on the other hand do not face similar competition in the public sector. ${ }^{1}$

Federal agencies are also imbued with missions by federal statute and populated by professionals beholden to the norms of both their profession and to the organization. This promotes the type of stability, for better or worse, that increases the consistency and reliability of information from the federal bureaucracy. This is not to say that bureaucrats are less self-interested than organized interests, but simply that they do not face the same economic pressures (both external and internal) that private sector groups face.

What of the accuracy of information? The tendency for biased information is in part mitigated by two factors. Bureaucrats, by virtue of longevity, are engaged a repeated interaction, or game, with Congress in an effort to

\footnotetext{
${ }^{1}$ Little scholarship exists on the effect on information of government contracting, which may introduce a degree of market-like pressures to the public sector.
} 
define policy problems (Aberbach, 1990; Workman, 2015). In the long run interaction, preferences are revealed. This means is that while bureaucrats may very well bias their provision of information to policymakers, policymakers are likely aware of the biases (detected over decades of interaction) and are able to weight these biases more accurately (compared to groups) in their decision calculus. The result is that, even if the provision of information is biased, repeated relationships allow for the systematic adjustment of stance based on even biased information. Note that this is true if bureaucrats are consistent in supplying information. In short, smaller variance sometimes trumps pin-point accuracy.

Given the competitive institutional dynamics of policy issues and boundaryspanning problems, information not provided by one entity, will assuredly be supplied by another in an effort to steer policy debate and influence problem definitions (Workman and Shafran, 2015). Private information is revealed in the competition for ideas. The ideas and argument presented above lead to the general expectation that bureaucrats will be influential in processes of congressional search and problem definition. Research on communication in social psychology offers a convenient way to gauge the prominence of bureaucrats in policy debates.

\section{General Implications}

Congressional hearings serve multiple purposes including information gathering. Bureaucrats are important sources of policy- and politically-relevant information. Where policy is concerned, bureaucrats have expertise on particular issues, having worked on problems for long periods of time. Bureaucrats are also important sources of information during partisan transitions in two ways. First, they offer insights into policy making not available elsewhere for new legislators. Second, political appointees in particular are indicators of executive branch stances on issues. We argue that the main driver of bureaucratic prominence in the hearing process is the degree of uncertainty in developing a working problem definition. Where uncertainty concerning the nature of the problem is high, we expect the participation and prominence of federal bureaucrats to increase for reasons that follow from the discussion in Section 3. This leads to our first hypothesis.

Hypothesis 1 (Bureaucratic Participation) Increases in congressional uncertainty about problem definitions will lead to increases in the frequency of bureaucrats testifying at congressional hearings. 
In particular, bureaucrats are likely to be most prominent in the defining of policy problems, as opposed to choice of solutions. This is in part because preferences attached to policy problems are likely less "sticky" than those attached to solutions. This also suggests that bureaucrats are less prominent where solutions are "locked in" or the solution itself defines the problem. While it is true that both politicians and bureaucrats have welldefined preferences over different policy solutions (e.g., market mechanisms versus regulation), it is less clear that they hold different preferences regarding particular policy problems (e.g., investor protection versus accounting rules in the case of securities regulation). Participation in the hearing process provides bureaucrats an important opportunity to aid in defining the parameters of policy debate, even if there is less influence over the solution set.

Where the defining of policy problems is concerned, bureaucratic prominence, and not just participation, is also an important consequence of uncertainty. In the study of communications in social psychology, research has long identified the importance of primacy in persuasion (Hovland, 1966; Tetlock, 1983). That is, the most influential arguments are those made first, in part because these are remembered and frame the debate both during and following consideration of the problem, respectively. Consistent with this general reasoning, we expect that as congressional uncertainty increases, not only will bureaucratic participation increase, but their prominence, or primacy in the policy debate, will also increase. Bureaucrats will occupy primary positions in the hearing process affording them an opportunity to define the issues and frame the debate. This leads to our second hypothesis.

Hypothesis 2 (Bureaucratic Primacy) Increases in congressional uncertainty about problem definitions will lead to increases in bureaucratic primacybureaucrats will more frequently appear first in the hearing testimony.

The same general arguments that allow us to distinguish between the participation of federal bureaucrats and organized interests also imply a distinction between the different types of federal bureaucrats that are likely to be prominent under conditions of uncertainty. For reasons of reliability, and stability of the information provided, conditions of uncertainty are likely to foster the participation and prominence of career federal bureaucrats. Careerists are likely to be a much more reliable and consistent supply of information generally. This is because they are not subject presidential 
personnel systems aimed at ideological congruence, and are not subject to the strong shifts in political climate faced by political appointees. In the repeated game discussed in Section 4, they hold stronger bonds with members of Congress and committee staff. Therefore, we expect that under conditions of uncertainty surrounding problem definitions, not only will federal bureaucrats be more prominent players in policy making, but the participation of career bureaucrats will also increase.

Hypothesis 3 (Careerists Participation) Increases in congressional uncertainty about problem definitions will lead to increases in the frequency of career bureaucrats testifying at congressional hearings.

\section{Problem Definition in Business and Financial Regulation}

In examining our assertions about bureaucratic participation and prominence in policy making, the focus of our study is congressional attention to business and financial regulation from January 1983 through September 2005 in the United States. Business and financial regulation is not only a perennially prominent issue on the governmental agenda, but it also activates strong systemic impulses for the mobilization of organized interests. In this way, business and financial regulation is unlike macroeconomic policy, where it might be expected that bureaucrats are much more central regardless of the uncertainty characterizing policy making. In order to examine the participation of federal bureaucrats in congressional policy making, we use a data set that allows us to trace policy making on business and financial regulation over long periods of time. In particular, we have characterized congressional uncertainty primarily in terms of the definition of policy problems. This places weighty importance on our ability to gauge the different substantive dimensions of business and financial regulation that are the subject of governmental attention at any one point in time.

The indicator used to operationalize the content of congressional attention to (and uncertainty in) business and financial regulation is the archive of congressional hearings housed at the Comparative Agendas Project (CAP). ${ }^{2}$

\footnotetext{
${ }^{2}$ The data used here were originally collected by Frank R. Baumgartner and Bryan D. Jones, with the support of National Science Foundation grant numbers SBR 9320922 and 0111611, and are distributed through the Department of Government at the University of Texas at Austin. Neither NSF nor the original collectors of the data bear any responsibility for the analysis reported here.
} 
Using the Comparative Agendas Project's archive of congressional hearings and topic coding scheme, we identified congressional hearings each month from January 1983 through September 2005 dealing with business and financial regulation. ${ }^{3}$ Because coding at the hearing level can mask the importance, or unimportance, of some issues, we use a count of the number of hearing days for the various topics in business and financial regulation for each month of the time period under study. ${ }^{4}$ In all, there were 4,019 congressional hearing days devoted to business and financial regulation over the period under study (see Figure 1).

Each hearing provided by the CAP included the identifying Congressional Information Service (CIS) number and using these we recorded each witness (both federal bureaucrats and organized interests) present at each hearing on business and financial regulation over the time period under study via LexisNexis Congressional. We recorded the witness' names, along with their title and affiliation as well as their order of testimony and date of appearance before Congress. This yielded a total of 25,681 witnesses over the period under study. Using these indicators, we constructed measures of congressional uncertainty in business and financial regulation and the participation and prominence of federal bureaucrats over time.

Figure 1 displays the count of congressional hearing days devoted to the various topics making up business and financial regulation in the CAP topic coding scheme. Figure 1 shows that while congressional attention is dispersed across quite a few topics, four major sub-issues dominant congressional attention to business and financial regulation. Corporate management (10.6\%), which includes mergers and acquisitions, financial institutions regulation (17.2\%), securities and exchange regulation (11.5\%), and small business programs (21.3\%) garner the lion's share of congressional attention in this major policy issue. Note that business and financial regulation contains sub-issues or elements which span both governmental regulation of business as well as governmental promotion of business (as is largely the case in small

\footnotetext{
${ }^{3}$ The Policy Agendas Project codes each hearing into a set of 19 major topic categories dealing with the substance or content of each hearing, and nested within these, they are coded into one of 226 subtopic codes. For a full explication of the topic coding scheme see www.comparativeagendas.net.

${ }^{4}$ For instance, a hearing lasting one day on the regulation of white-water rafting in West Virginia is likely not as important as a hearing lasting ten days on the regulation of large financial institutions.
} 


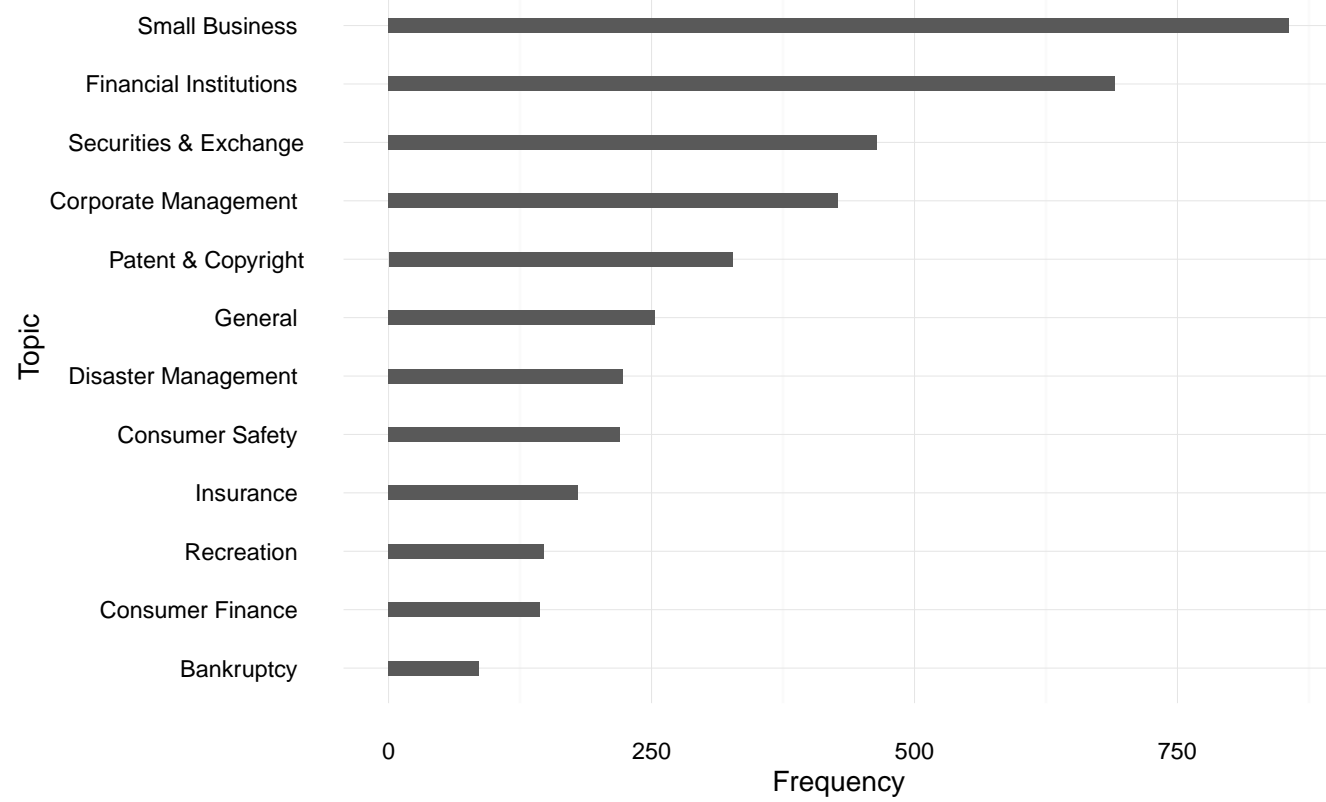

Figure 1: Congressional Hearing Days on Business and Financial Regulation by Topic.

The figure displays the total frequency of congressional hearing days on business and financial regulation by topic from January 1983 through September 2005.

business, disaster management, and patent and copyright regulation). A cursory glance at Figure 1 also helps to put the 2008 financial crisis and proposed solutions to this crisis in perspective. While attention and solutions centered on regulation, and the propping up, of financial institutions and securities markets, the "other" side of the problem, bankruptcy and consumer finance, received very little attention over the time period under study leading up to the crisis.

In any event, Figure 1 shows that while some components of business and financial regulation receive low quantities of attention in Congress, the spread of attention across topics, or elements of the "problem" of business and financial regulation can be quite broad. In terms of gauging uncertainty in this issue area where policy substance is concerned, this fact calls for a measure that is able to not only tap into the levels of attention, but also capture the spread of this attention across topics. 


\subsection{Measuring Congressional Uncertainty and Bureaucratic Participation}

In order to measure the uncertainty contained in congressional efforts to understand the evolving problem of business and financial regulation, we use our hearings data to construct a measure of hearing entropy over the time period under study. Entropy, or Shannon's H (Shannon and Weaver, 1949), is used to characterize the uncertainty associated with incoming information. While it was originally developed in the mathematical theory of communication (Pierce, 1980), it has also been used in the study of public policy more recently (Sheingate, 2006; Boydstun, Bevan, and Thomas, 2014). The chief idea behind entropy is that incoming information should allow the receiver to learn something new about the environment from which the information emanated. If the receiver can "categorize" new information quite easily, then the receiver has learned nothing new. However, if the information is difficult to categorize then the receiver is able to learn more about the environment from which the information is coming. Formally, entropy is defined $^{5}: \sum_{i=k}^{k} p * \log _{k}(1 / p)$.

In this case there are $k$ topics in which to categorize information and the proportion $(p)$ of cases falling in any one topic multiplied by the log (base = $k$ ) of the inverse of the proportion of that topic. For our purposes, we want a measure of the uncertainty contained in the agenda for business and financial regulation over the time period under study. The CAP contains 12 sub-topics or issues falling under the broad area of business and financial regulation (see Figure 1). Thus, for our purposes, $k=12$. Summing across all $k$ yields a measure of the uncertainty contained in the entire system for categorization of business and financial regulation theoretically bound at 0 and 1 , where increasing values indicate increasing entropy-increasing uncertainty in the definition of the problem.

Our measure of the participation of federal bureaucrats is gleaned from our expansive data collection efforts on the witnesses appearing at congressional hearings on business and financial regulation. We count the number of federal bureaucrats appearing at congressional hearings on business and financial regulation as identified from the CAP archive of hearings. In addition to counting the number of federal bureaucrats appearing at these hearings, we collected the order in which these bureaucrats testified in relation to

\footnotetext{
${ }^{5}$ Entropy in the original Shannon formulation is often written $-\sum_{i=k}^{k} p * \log _{k} p$. Here, we use $\frac{1}{p}$ to eliminate the need for the negative sign in front
} 
other bureaucrats and organized interests. Our second measure of bureaucratic participation pertains to the primacy of bureaucrats at the hearings, in terms of the older social psychological research. We count the number of bureaucrats each month in our analysis who testify first in the hearings. ${ }^{6}$

From this data set, we were able to generate a list of all federal bureaucrats appearing at these hearings. Using this list, we were able to classify career bureaucrats participating in the hearings by taking the names on the list and cross referencing them with the Plum Book for each associated time period, which allowed us to ascertain the job classification of each federal bureaucrat (Senior Executive Service, political appointee, careerist, etc.) (Lewis, 2008). By matching federal bureaucrats to the Plum Book, we obtained a count of the number of career bureaucrats participating in hearings on business and financial regulation over time.

Figure 2, panel (a) displays the count of federal bureaucrats appearing at congressional hearings on business and financial regulation over the period of study. The first thing to note is that the number of bureaucrats appearing varies quite a bit from month to month. In general, bureaucrats appeared in greater numbers during the George H.W. Bush and Clinton administrations. Bureaucrats were less pervasive in the hearing process during the first term of George W. Bush, however, these numbers would likely increase once the financial crisis is taken into account. The mean number of bureaucrats appearing in business and financial regulation across the monthly data is 16 with a standard deviation of 14. Participation ranged from 0 appearances occurring more than once to 63 in March of 1984.

Fewer bureaucrats appear at hearings after Republicans take control of Congress in 1995. The mean prior to 1995 is 20 bureaucrats per month, while the mean afterward is 12 ( $\mathrm{p}<.001$ for a simple test of means). The period after Republican control of Congress was generally prosperous economically speaking as well, which likely contributes to the lower numbers of bureaucrats. After all, fewer problems in the policy making environment implies less need for bringing in bureaucrats to define those problems. Figure 2 displays the frequencies of bureaucrats across party control of Congress in panel (b) and presidential administration in panel (c). Figure 2, panels (b) and (c)

${ }^{6}$ The social psychological literature points not only to primacy (who speaks first), but also to recency (who speaks last) in the persuasiveness of information. While someone always testifies first, the length of testimonies (in terms of the numbers of individuals appearing) varies greatly, making it difficult to collect a systematic measure of recency. 


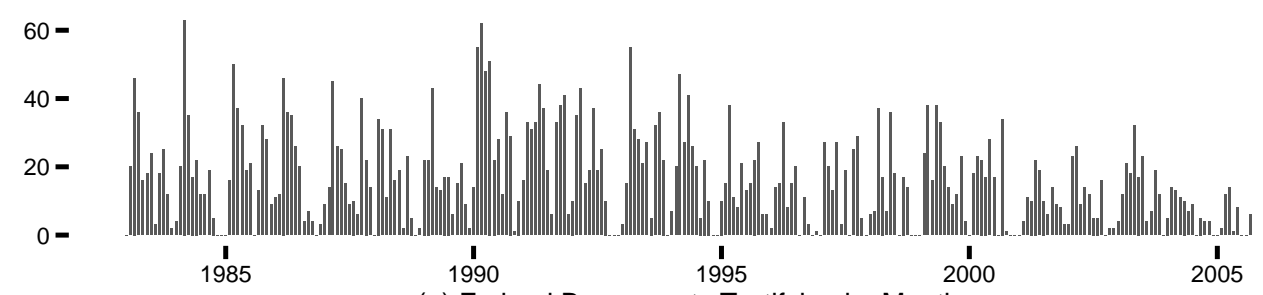

(a) Federal Bureaucrats Testifying by Month
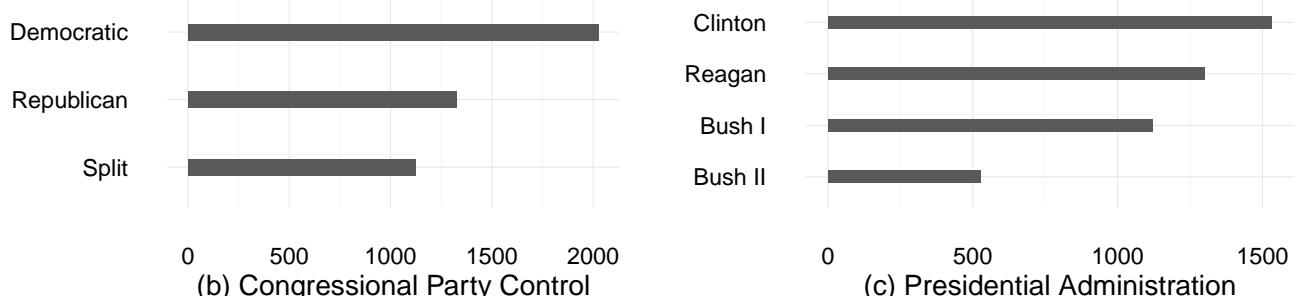

Figure 2: Participation of Federal Bureaucrats in Business and Financial Regulation.

Panel (a) displays the frequency of federal bureaucrats appearing in congressional hearings on business and financial regulation each month from January 1983 through September 2005. Panel (b) displays the total frequency over the period broken out by party control in Congress $\left(\chi^{2}=50, \mathrm{p}<.001\right)$. Panel (c) displays the total frequency for the period broken out by presidential administration $\left(\chi^{2}=70, \mathrm{p}<.001\right)$. 
show that there are significant differences in bureaucratic participation by party control of Congress and by presidential administration.

Panel (c) of Figure 2 shows a higher number of bureaucrats appear under the Clinton administration, probably as a result of ideology and also the Republican takeover of Congress. The highest annual average of bureaucratic appearances occur during the George H.W. Bush administration (280 bureaucrats) and the lowest under George W. Bush (105 bureaucrats) . Whether this was due to war or the economic woes of the late 1980s and early 1990s, Figure 2, panel (c) prevents a clear story of partisanship in presidential administration as a driver of bureaucratic participation in congressional hearings. Panel (b) of Figure 2 also shows that democratically controlled Congress's increase bureaucratic participation in the hearings. This makes sense if one assumes that democrats are more apt to seek out problem definitions and solutions that favor a governmental role in the economy and society.

Moving to congressional uncertainty about problem definitions, Figure 3 displays the relationship between bureaucrats at congressional hearings on business and financial regulation and the entropy characterizing these hearings. Figure 3 includes a lowess smooth line with $95 \%$ confidence interval represented by the shaded area. The scatter plot of Figure 3 shows the relationship to be positive and exponential. ${ }^{7}$ In general, Figure 3 is suggestive of the relationship between congressional uncertainty, at least measured as hearing entropy in days, and levels of participation by federal bureaucrats in business and financial regulation. The hearing entropy and bureaucratic participation correlate at .64 $(\mathrm{p}<.001)$. Hearing entropy also displays considerable variation over the period under study. With a mean of .54 and standard deviation of .25, its empirical range in this instance almost encompasses its theoretical range at 0 and .91. In other words, there are times in the series where congressional attention is very focused on a few dimensions of the problem, and is hence more certain about the nature of the problem. This is balanced by periods where uncertainty is so prevalent as to rule the day.

Figure 3 sets the stage for a more rigorous examination of the influence of congressional uncertainty on the participation of federal bureaucrats in

\footnotetext{
${ }^{7} \mathrm{~A}$ plot of the logs of these two variables reveal a strictly linear relationship characterized by heteroskedasticity.
} 


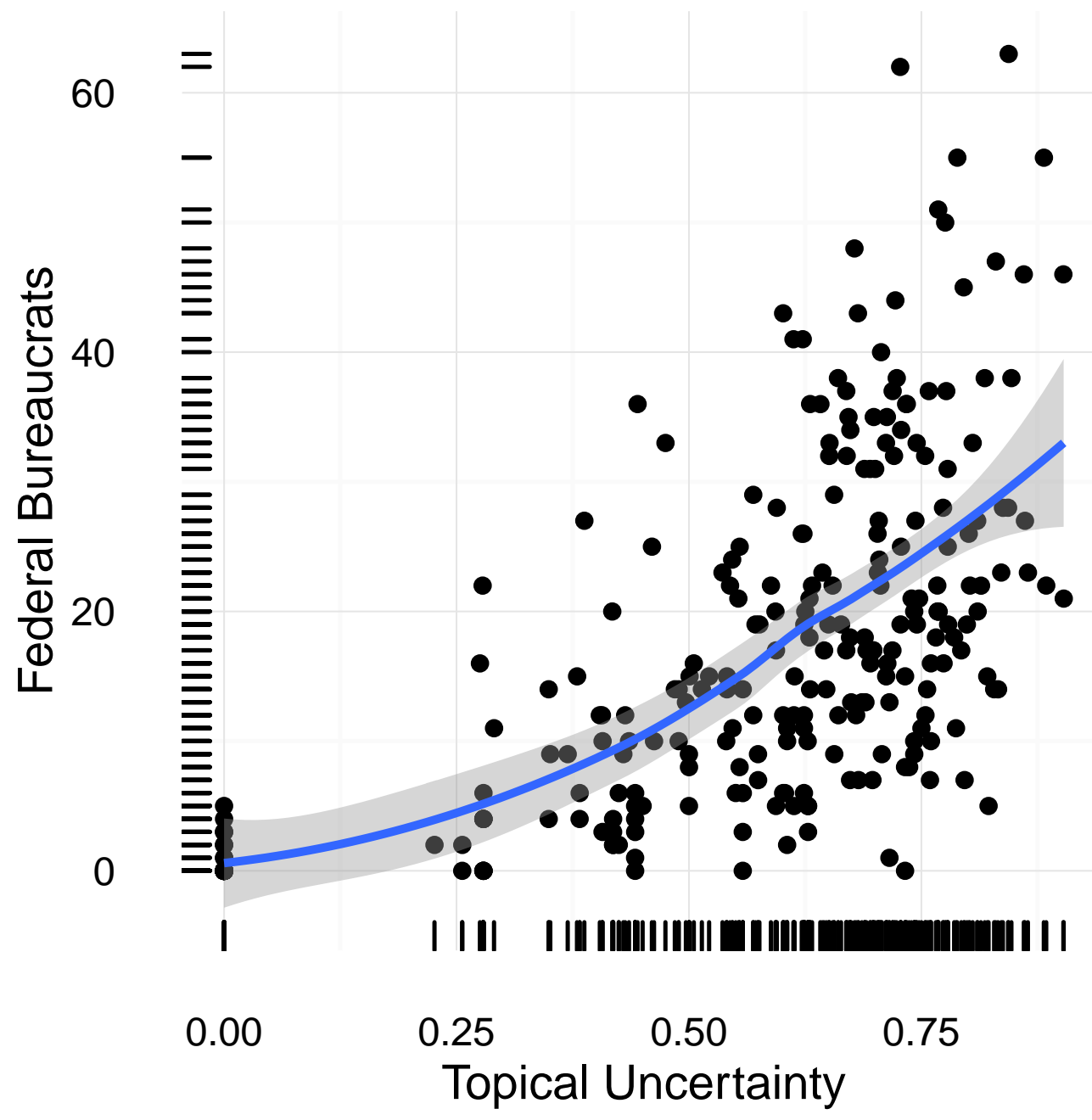

Figure 3: Congressional Problem Uncertainty and Federal Bureaucrats in Business and Financial Regulation.

The figure displays a scatter plot of the relationship between congressional hearing entropy and the participation of federal bureaucrats in business and financial regulation. The blue line displays a lowess smooth of the same relationship with bandwidth set at two thirds and includes a $95 \%$ confidence interval covered by the shaded area. 
hearings on business and financial regulation. The figure is suggestive of the causal influence of congressional uncertainty concerning problem definition on the levels of participation by bureaucrats. The figure is also suggestive of our approach to modeling this influence.

\section{Modeling Bureaucratic Participation and Prominence}

Our measure of bureaucratic participation is a count of federal bureaucrats appearing in congressional hearings on business and financial regulation. Since the measure is a count, its distribution contains properties making it more amenable to statistical models tailored to count processes. In particular, the histogram of monthly counts of federal bureaucrats reveals the typical distribution of a count variable, except it contains an excess of zeros (see Figures 2 and 3). This fact recommends hurdle or "zero-inflated" count models as an appropriate statistical tool for modeling the influence of congressional uncertainty on bureaucratic participation and prominence.

Zero-inflated count models are useful in modeling data in which zeros can arise from 2 different processes. Zeros might arise as a product of the same data-generating process leading to positive counts. Alternatively, zeros could arise from a separate process. For example, the hearings on business and financial regulation might lead to an absence of bureaucrats arising out of greater certainty regarding the problem definition and a particular configuration of political influences. Alternatively, an absence of bureaucrats might also be due to an excess of hearings for purposes of bill mark-ups, which often have no witnesses at all. This second process leading to a zero has little to do with the underlying process generating the positive counts (politics and the uncertainty surrounding the issue), but is instead a product of the legislative calendar.

Zero-inflated count models address this distinction by allowing zeros to arise from each of two separate models, which are combined to model data exhibiting excess zeros. The models contain a binomial component (most often logit or probit), which models the "excess" zeros, and a count component (usually poisson or negative binomial) to model the count process. After testing zero-inflated models against standard count model specifications, it was determined that the zero-inflated specification was a better approximation to the data than were the standard models. In addition, the zero-inflated negative binomial (ZINB) specification out-performed the zero-inflated poisson distribution as indicated by a Vuong likelihood ratio test comparing the 


$$
\begin{aligned}
& \ln \mathcal{L}=\left\{\begin{array}{l}
\ln \left(p_{i}\right)+\left(1-p_{i}\right)\left(\frac{1}{\left(1+\alpha \mu_{i}\right)}\right)^{\frac{1}{\alpha}} \text { for } y=0 \\
\ln \left(p_{i}\right)+\ln \Gamma\left(\frac{1}{\alpha}+y_{i}\right)-\ln \Gamma\left(y_{i}+1\right)-\ln \Gamma\left(\frac{1}{\alpha}\right)+\left(\frac{1}{\alpha}\right) \ln \left(\frac{1}{\left(1+\alpha \mu_{i}\right)}\right)+y_{i} \ln \left(1-\frac{1}{\left(1+\alpha \mu_{i}\right)}\right) \forall y>0
\end{array}\right. \\
& \mu=\exp \left(\mathbf{X}_{i} \beta\right)
\end{aligned}
$$

In Equation (1), the excess of zeros is accounted for in the logit function when $y=0$, while the counts are modelled in the negative binomial function for all $y>0$. The $\alpha$ parameter accounts for the over-dispersion often characterizing count data. Equation (2) shows that the systematic component for the counts are modeled using $\mu=\exp \left(\mathbf{X}_{i} \beta\right)$, where $\mathbf{X}$ is the matrix of covariates in our model and $\beta$ is a vector of estimated parameters. Of these, we are primarily interested in the effect of topic entropy on bureaucratic participation.

For an expeditious discussion below, we present results for the count components of the ZINB models only. We believe the particular process giving rise to the excess zeros (the binomial component) to be much more a function of institutional peculiarity and scheduling not easily addressed with our data. As such, the binomial component contains only the mean and our entropy measure. ${ }^{8}$ Second, it is the count component of the model in which we are interested, as it pertains directly to our hypotheses. Full model results for the ZINB specifications are available in Appendix A. We would merely note, however, that in each of the 3 full models presented in Appendix A, topic uncertainty is a robust and significant predictor in the logit equation. Each of these coefficients is signed negatively, indicating that when congressional topic uncertainty is high, instances where federal bureaucrats are absent significantly decrease. This is subtle and general support for our hypotheses in Section 4.

Figure 4 displays the regression results for the ZINB model of overall bureaucratic participation in congressional hearings on business and financial regulation. The regression estimates are presented as a "ropeladder" in Panel (a) of the figure. The parameter estimates also contain 95\% confidence intervals showing the uncertainty around these estimates. The estimates, and

\footnotetext{
${ }^{8}$ We tested the other influences appearing below, none of which were useful in predicting the excess zeros.
} 
their confidence intervals, are the result of 10,000 simulations of the model and their standard deviations. ${ }^{9}$ The dependent variable in Panel (a) of Figure 4 is a monthly count of federal bureaucrats appearing at hearings on business and financial regulation for the time period under study and pertains to Hypothesis 1.

In addition to our measure of congressional hearing entropy, the model contains binary variables for unified Republican and unified Democratic control of the institutions of government and legislative ideology measured in the first dimension of Pool and Rosenthal's NOMINATE scores (Poole and Rosenthal, 1997). In addition, we include a variable for party transitions in Congress. We expect that unified Republican governments will decrease the participation of federal bureaucrats, while unified Democratic governments will increase their participation due to different preferences over the locus of policy implementation with Republicans preferring private sector solutions. Likewise, we expect increases in the NOMINATE score, indicating increased conservatism, to be negatively related to bureaucratic participation. The model also contains a variable for party transition in Congress. This variable takes a value of one for each of the first six months following a change from Republican to Democratic control or vice versa. This is because we expect these transitions to lead to new efforts to redirect the general policy direction of the bureaucracy. Finally, the model contains the percent of party unity votes in Congress tabulated from data on polarization in Congress (McCarty, Poole, and Rosenthal, 2006). The nominate scores and party unity data were obtained from the web-site maintained by Keith Poole. ${ }^{10}$

Panel (a) of Figure 4 shows that the entropy associated with congressional hearings on business and financial regulation does increase the participation of federal bureaucrats in these hearings. Along with congressional uncertainty, unified Republican government and increasing congressional conservatism are associated with decreases in the number of bureaucrats participating in the hearings. Unified Democratic control of government is also associated with decreases participation by federal bureaucrats, although this influence is barely statistically significant. The fact that the intercept in the model, capturing the influence of divided government, is not statistically sig-

\footnotetext{
${ }^{9}$ In addition, we performed 1,000 bootstrapped simulations of the regression coefficients. These bootstrap estimates showed that no parameter estimate contained bias of greater than \pm .005 .

${ }^{10}$ The data are made freely available by Poole at http://voteview.com/.
} 
nificant (note that its confidence interval crosses zero) makes the influence of partisan control of government a bit harder to discern. The only solid conclusion is that fewer bureaucrats appear at the hearings under unified republican control. Party transition also fails to reach conventional levels of statistical significance.

Note that Figure 4 shows that increases in party polarization, measured as the percentage of party unity votes in Congress, are associated with increases in participation by federal bureaucrats. The estimate for party polarization is sizeable even though the confidence interval for the estimate is large. It is possible that the pitched political conflict within the chambers of Congress is in part manifested in efforts to steer the bureaucracy. However, even under party unity, one party holds majority status. It could also be the case that legislative conflict makes imperative the need to justify majority party stances with testimony from bureaucratic experts. Further, in preliminary analyses, the relationship between party unity votes and bureaucratic participation varied a great deal between the House of Representatives and Senate. It is possible that combining the measures contributed to the uncertainty surrounding its influence.

Panel (b) of Figure 4 contains the simulated influence of entropy in congressional hearings on business and financial regulation on the appearance of federal bureaucrats at these hearings. The figure was constructed by conducting 1,000 simulations of the influence of entropy on bureaucratic participation at each 0.01 of hearing entropy across its empirical range. The line represents the prediction of the model pursuant to these simulations and the shaded area represents the $95 \%$ confidence interval for each prediction, also a function of the 1,000 simulations of the model. As entropy increases across its range, there is a resulting increase of around 35 federal bureaucrats participating in the hearings. As mentioned above, entropy varies quite a bit. A similar plot containing simulations for a move in entropy from minus one standard deviation to plus one standard deviation yields and increase of around 20 federal bureaucrats. In general, Figure 4 supports the notion that increases in congressional uncertainty, at least measured in hearing entropy, are related to increases in the participation of federal bureaucrats in the issue of business and financial regulation. Figure 4 offers substantial support for Hypothesis 1 concerning bureaucratic participation.

Figure 5 displays the same statistical model for bureaucratic primacy in congressional hearings. The dependent variable in Panel (a) of Figure 5 is a monthly count of the number of bureaucrats testifying first at congressional 


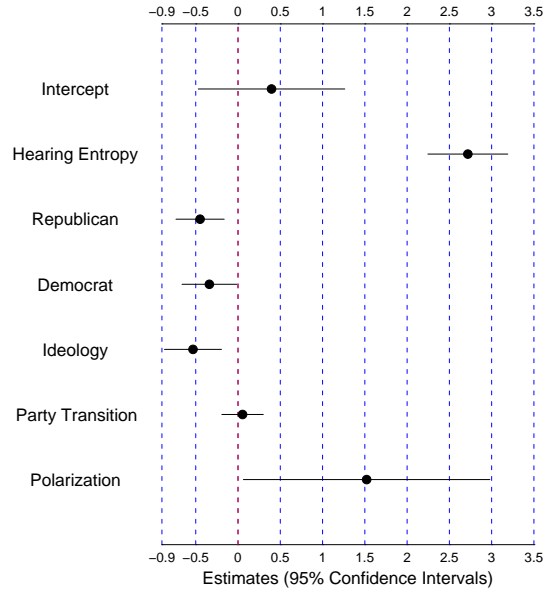

(a) Participation in Congressional Hearings.

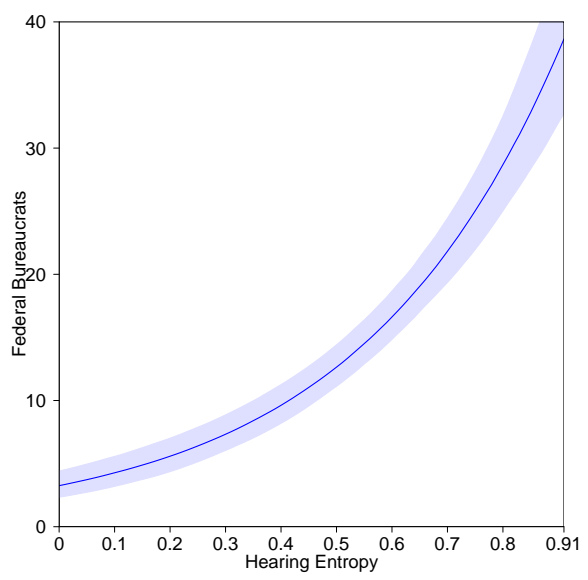

(b) Hearing Entropy and Predicted Federal Bureaucrats.

Figure 4: Congressional Uncertainty and Federal Bureaucrats in Business \& Financial Regulation.

Panel (a) contains the estimates for the count process of a zero-inflated negative binomial regression of the number of federal bureaucrats participating in congressional hearings for the count process in the model. Estimates and $95 \%$ confidence intervals are the product of 10,000 simulations. Panel (b) contains the simulated influence of hearing entropy on the number of bureaucrats appearing in hearings on business and financial regulation. These predictions are the product of 1,000 simulations at each 0.01 of hearing entropy across its range. The panel includes $95 \%$ confidence intervals for the predictions. 
hearings on business and financial regulation. Given increased uncertainty, we expected that bureaucrats would not only participate in greater numbers as shown by Figure 4, but also that their prominence, here measured as primacy, in the hearings would increase as Congress struggled to define the issues. As with bureaucratic participation, Panel (a) of Figure 5 shows that congressional uncertainty is positively, and significantly, related to increases in the primacy of federal bureaucrats at hearings. The coefficient is only slightly smaller, but remains robust. Consistent with bureaucratic participation, unified Republican control of government seems to lead to lower bureaucratic primacy in the hearings. While the impacts of congressional ideology and unified democratic control of government are not statistically distinguishable from zero, the influence of polarization in Congress and party transitions seem to increase bureaucratic primacy. Party transitions barely exceed the requirements for statistical significance at the conventional $95 \%$ level. And while the confidence interval around polarization remains quite large, its parameter estimate is of larger size, making its positive influence on bureaucratic primacy more certain. While changes in the party in power in Congress do not seem to increase the participation of federal bureaucrats, it possibly brings them front and center in policy debates in business and financial regulation. Likewise, increased legislative conflict seems to increase the prominence of federal bureaucrats in policy debates, wanted or not. While bureaucrats are often viewed with disdain in popular images of government, bureaucrats are quite often marshalled to lend legitimacy to political claims, whether made by politicians or organized interests, especially where the burdens of evidence are high.

Panel (b) of Figure 5 shows a similar plot of predicted primacy as in the model for bureaucratic participation. Again, the point estimates forming the line and the shaded area representing the $95 \%$ confidence interval are the result of 1,000 simulations at each 0.01 of hearing entropy across its empirical range. Panel (b) shows that as hearing entropy moves over its range, there is a resulting increase of about 16 federal bureaucrats testifying first in hearings on business and financial regulation. A similar plot of predicted primacy resulting from a shift from minus to plus one standard deviation results in an increase of six bureaucrats testifying first at the hearings. The monthly mean of federal bureaucrats testifying first is eight, with a range of zero and 34. Figure 5 is in general supportive of the notion that congressional uncertainty not only increases bureaucratic participation in the hearings, but also increases the prominence of these bureaucrats in the policy debate. 


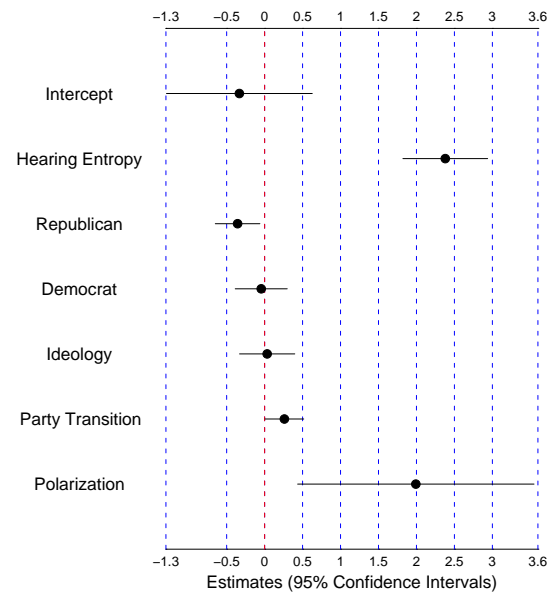

(a) Bureaucratic Primacy in Hearing Testimony.

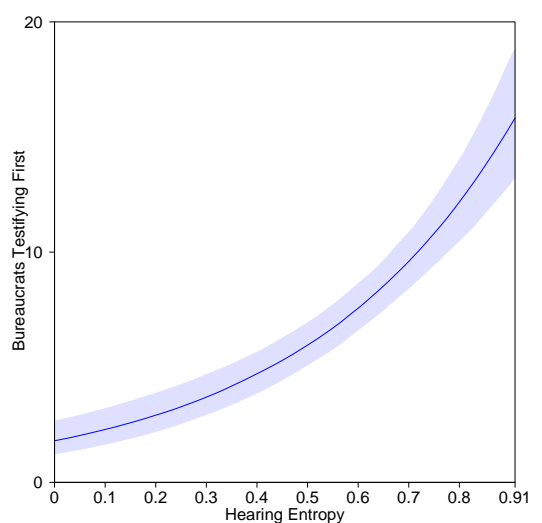

(b) Problem Uncertainty and Bureaucratic Primacy.

Figure 5: Problem Definition and Bureaucratic Primacy in Congressional Hearings.

Panel (a) contains the estimates for the count process of a zero-inflated negative binomial regression of the number of federal bureaucrats testifying first in congressional hearings on business and financial regulation. These estimates are the product of 10,000 simulations and include 2 standard deviation (95\%) confidence intervals for the estimates. Panel (b) contains the simulated influence of hearing entropy on the number of bureaucrats testifying first in hearings on business and financial regulation. These predictions are the product of 1,000 simulations at each 0.01 of hearing entropy across its range. The panel includes simulated $95 \%$ confidence intervals for the predictions.

This is suggestive of the role played by federal bureaucrats, especially under conditions of extreme uncertainty, in shaping the development of working problem definitions. It further suggests that federal bureaucrats not only implement policies and represent constituent or client group interests, they are central in structuring the resulting policy debates. In doing so, they lend legitimacy to some claims and de-legitimize others. Figure 5 offers support for Hypothesis 2 concerning bureaucratic primacy.

If bureaucratic participation and prominence increase under congressional uncertainty for the reasons outlined above, it should be the case that congressional uncertainty increases the levels of participation not only of bureaucrats in general, but particularly of career bureaucrats. We have argued that a concern for reliable information with a very low variance even if a little biased helps fuel congressional demand for bureaucratic participation in policy making. Careerists in the federal bureaucracy likely hold an edge not only on organized interests, but also on their superiors at the apex of 
the bureaucracy in this regard. Shielded from exposure to intense political pressure, unlike their peers at the top of the bureaucracy, careerists likely provide a more consistent and reliable source of information than their counterparts. Given this, their participation under conditions of uncertainty is vital even if their expertise is biased. Their longevity fosters the ability of members of Congress to weight their expertise in a way not possible with organized interests or political appointees. The mean number of careerists participating monthly in hearings on business and financial regulation in the time period under study is 4.7 (standard deviation of 4.5), with a range of zero and 24. Levels of participation by careerists are especially sensitive to uncertainty at its higher levels.

Figure 6 displays the same analysis of participation by career bureaucrats in business and financial regulation as for general levels of bureaucratic participation and primacy in the two previous figures. It supports generally the arguments underlying Hypothesis 3 concerning topical uncertainty and participation by career bureaucrats. The dependent variable in Panel (a) of Figure 6 is the monthly count of career bureaucrats appearing at congressional hearings on business and financial regulation. Once again, congressional hearing entropy is associated with increases in careerist participation in business and financial regulation. Along with hearing entropy, unified Republican government decreases levels of participation by careerists. As well, polarization in Congress increases participation by careerists, albeit with a sizeable confidence interval. Panel (b) of Figure 6 displays the predicted counts of federal career bureaucrats as hearing entropy varies across its range. Again, both these point estimates represented by the line, and 95\% confidence interval represented by the shaded area are the result of 1000 simulations at each 0.01 of entropy through is range. Panel (b) predicts an increase of around 10 careerists as entropy traverses its range. A similar plot of predicted counts as entropy moves from minus to plus one standard deviation predicts an increase of about 5 career bureaucrats at the hearings on business and financial regulation.

Confronting problems rife with uncertainty, the findings of Figure 6 highlight the importance of volatility and variance in political and policy decision making. Especially under uncertainty, it is not enough that the stream of communication from relevant participants provide information. The information also must be characterized by consistency and reliability, if only for a point of reference in a volatile decision making environment. To the degree that careerist bureaucrats represent consistency in the system of governmen- 


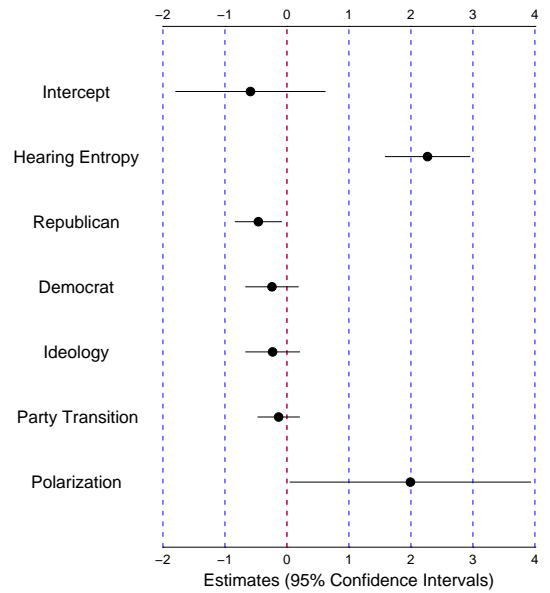

(a) Career Bureaucrats in business and financial regulation.

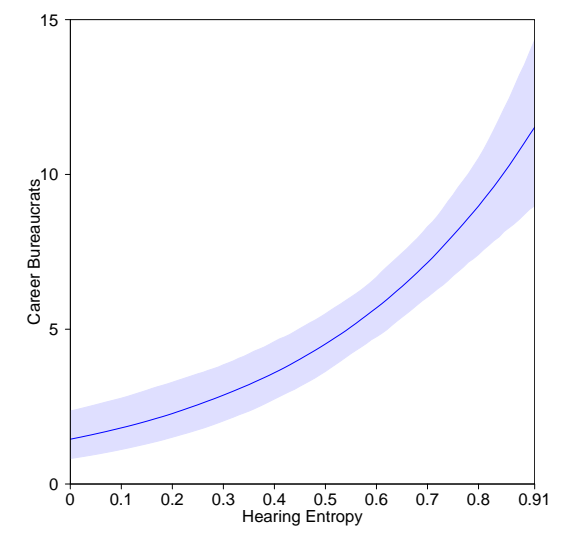

(b) Hearing Entropy and Predicted Career Bureau-

Figure 6: Problem Definition and the Prominence of Career Bureaucrats.

Panel (a) contains the estimates for the count process of a zero-inflated negative binomial regression of the number of career federal bureaucrats participating in congressional hearings on business and financial regulation. Estimates are the product of 10,000 simulations of the model and include two standard deviation (95\%) confidence intervals. Panel (b) contains the simulated influence of hearing entropy on the number of career federal bureaucrats participating in hearings on business and financial regulation. These predictions are the product of 1,000 simulations at each 0.01 of hearing entropy across its range. The panel includes simulated $95 \%$ confidence intervals for the predictions.

tal communication, these analyses highlight the need for research to be more attentive to variability in choice situations.

\section{Discussion and Conclusions}

Taken together, the models presented are supportive of the notion that Congress tends to rely more heavily on federal bureaucrats when faced with increasing uncertainty about the nature of problems, at least in the important issue of business and financial regulation. As uncertainty about the most relevant topical dimensions of the issue increase, federal bureaucrats are called to participate in greater numbers. Further, these bureaucrats are often in prominent positions within the hearing process, testifying first, setting the agenda, and perhaps structuring the policy debate. Finally, not only do bureaucrats in general participate in greater numbers, but careerists, likely those best positioned to reduce uncertainty, participate in numbers that far 
outstrip their usual involvement.

The theorizing and analysis presented here draws attention to three facets of congressional search and the information supply by the federal bureaucracy. First, the findings are supportive of the notion that difficulty in defining problems, and developing working understandings, is a prime consideration for members of Congress when engaging in search processes. Members of Congress do not micro-manage bureaucrats, but neither are they left at their mercy when it comes to information provision. While dependent on information from bureaucrats, interest groups, academics, and experts of all types, the analyses strongly suggest that members of Congress, working in committee especially, are able to navigate this uncertainty and craft flows and blends of information that allow for adaptable policymaking.

Second, the analyses highlight the valuable role of the federal bureaucracy in generating information, shaping problem definitions, and influencing policy agendas (Workman, 2015). Far from mere implementers of legislation, court decisions, and presidential directives, bureaucrats are influential at the agenda setting and problem definition phase of the policy process. This front-end role of bureaucracy in the system of information processing has been under-appreciated in the literature.

Third, the analyses point to the important distinction between information pertaining to positions versus information pertaining to problems. The prominence of careerists in instances of topical uncertainty suggests that members of Congress are sensitive to this distinction, seeking out careerists when problems call for consistent, reliable sources of information. The distinction between the problem and solution space of issues is also vital. Where solutions and preferences are settled, or where solutions wholly define their problems, we expect bureaucrats to recede in importance and prominence.

Overall, this research furthers our understanding of the system of information processing that characterizes the administrative state. Issue dynamism and the rise of boundary-spanning policy problems increasingly means the locus of expertise necessary to address problems lies between the traditional boundaries of subsystems and legislative jurisdictions. Given this, understanding how congressional search and bureaucratic information supply intersect is increasingly important as bureaucracies are brought into competition with one another and members of Congress are faced with a need to blend information to craft novel problem definitions that can handle these types of issues.

More practically, we collected 25,681 witnesses appearing in 4,019 days of 
congressional hearings on business and financial regulation. This represents a tremendous investment in resources to explore the mobilization of federal bureaucrats within this policy area. Understanding mobilization in any one issue area requires this sort of investment. There are some limitations of the analyses presented. Many of the political variables presented pertain to macro dynamics at the broadest level. Politics at the committee level would likely be a profitable extension of this research (Shafran, 2015).

\section{References}

Aberbach, J. D., 1990. Keeping a Watchful Eye: The Politics of Congressional Oversight. The Brookings Institution, Washington, D.C.

Baumgartner, F. R., Jones, B. D., 2014. The Politics of Information: Problem Definition and the Course of Public Policy in America. University of Chicago Press, Chicago.

Baumgartner, F. R., Jones, B. D., MacLeod, M. C., 2000. The evolution of legislative jurisdictions. The Journal of Politics 62 (2), 321-349.

Boydstun, A. E., Bevan, S., Thomas, H., 2014. The importance of attention diversity and how to measure it. Policy Studies Journal 42 (2), 173-196.

Dery, D., 1984. Problem Definitiion in Policy Analysis. University of Kansas Press, Lawrence, KS.

Epstein, D., O'Halloran, S., 1999. Delegating Powers: A Transaction Cost Politics Approach to Policy Making under Separate Powers. Cambridge University Press, New York.

Gailmard, S., Patty, J. W., 2013. Learning While Governing: Expertise and Accountability in the Executive Branch. Chicago University Press, Chicago.

Hovland, C. I., 1966. The Order of Presentation In Persuasion. Yale University Press, New Haven, CT.

Huber, J. D., Shipan, C. R., 2002. Deliberate Discretion?: The Institutional Foundations of Bureaucratic Autonomy. Cambridge University Press, New York. 
Jones, B. D., 2001. Politics and the Architecture of Choice: Bounded Rationality and Governance. Chicago University Press, Chicago.

Jones, B. D., Baumgartner, F. R., 2005. The Politics of Attention: How Government Prioritizes Problems. Chicago University Press, Chicago.

King, D. C., 1997. Turf Wars: How Congressional Committees Claim Jurisdiction. University of Chicago Press, Chicago.

Lewis, D. E., 2008. The Politics of Presidential Appointments: Political Control and Bureaucratic Performance. Princeton University Press, Princeton.

May, P. J., Jochim, A. E., Sapotichne, J., 2011. Constructing homeland security: An anemic policy regime. Policy Studies Journal 39(2), 285-307.

May, P. J., Koski, C., 2013. Addressing public risks: Extreme events and critical infrastructures. Review of Policy Research 30 (2), 139-159.

May, P. J., Koski, C., Stramp, N., Sep 2014. Issue expertise in policymaking. Journal of Public Policy 36 (02), 195-218.

URL http://dx.doi.org/10.1017/S0143814X14000233

May, P. J., Sapotichne, J., Workman, S., Aug 2006. Policy coherence and policy domains. Policy Studies Journal 34 (3), 381-403.

URL http://dx.doi.org/10.1111/j.1541-0072.2006.00178.x

May, P. J., Sapotichne, J., Workman, S., Nov 2009a. Widespread policy disruption and interest mobilization. Policy Studies Journal 37 (4), 793815.

URL http://dx.doi.org/10.1111/j.1541-0072.2009.00335.x

May, P. J., Sapotichne, J., Workman, S., May 2009b. Widespread policy disruption: Terrorism, public risks, and homeland security. Policy Studies Journal 37 (2), 171-194.

URL http://dx.doi.org/10.1111/j.1541-0072.2009.00309.x

May, P. J., Workman, S., 2009. President George W. Bush's Influence over Bureaucracy and Policy: Extraordinary Times, Extraordinary Powers. The Evolving American Presidency. Palgrave MacMillan, New York, Ch. The Paradox of Agency Issue Attention: The Bush Administration and Homeland Security.

URL www.amazon.com/dp/0230609546 
May, P. J., Workman, S., Jones, B. D., Oct 2008. Organizing attention: Responses of the bureaucracy to agenda disruption. Journal of Public Administration Research and Theory 18 (4), 517-541.

URL http://dx.doi.org/10.1093/jopart/mun015

McCarty, N., Poole, K. T., Rosenthal, H., 2006. Polarized America: The Dance of Ideology and Unequal Riches. The MIT Press, Cambridge, MA.

Miller, L. L., 2004. Re-thinking bureaucrats in the policy process: Criminal justice agents and the national crime agenda. Policy Studies Journal 4 (32), 569-588.

Olson, M., 1965. The Logic of Collective Action: Public Goods and the Theory of Groups. Harvard University Press, Cambridge.

Pierce, J. R., 1980. An Introduction to Information Theory: Symbols, Signals, and Noise, 2nd Edition. Dover Publications, Inc., New York.

Poole, K. T., Rosenthal, H., 1997. Congress: a political-economic history of roll call voting. Oxford University Press, New York.

Shafran, J., 2015. Whirlpools of information: Information processing in policy subsystems 1995-2010. Ph.D. thesis.

Shannon, C. E., Weaver, W., 1949. The Mathematical Theory of Communication. University of Illinois Press, Chicago.

Sheingate, A. D., 2006. Structure and opportunity: Jurisdiction and issue attention in congress. American Journal of Political Science 50 (4), 844859 .

Simon, H., 1996. The Sciences of the Artificial, 3rd Edition. The MIT Press, Cambridge, MA.

Tetlock, P. E., 1983. Accountability and the perseverance of first impressions. Social Psychology Quarterly 46 (4), 285-292.

Workman, S., 2015. The Dynamics of Bureaucracy in the US Government: How Congress and Federal Agencies Process Information and Solve Problems. Cambridge University Press, Cambridge. 


\section{Appendix A. Full Model Results}

Table A.1: Congressional Uncertainty and Bureaucratic Participation in Business Regulation

\begin{tabular}{lrrrr}
\hline & \multicolumn{2}{c}{ Count } & \multicolumn{2}{c}{ Zero Inflation } \\
& Estimate $^{\mathrm{a}}$ & St Error & Estimate & St Error \\
\hline Intercept & 0.39 & 0.43 & 1.15 & 0.42 \\
Congressional Uncertainty & 2.72 & 0.23 & -9.60 & 1.62 \\
Unified Republican & -0.45 & 0.14 & & \\
Unified Democratic & -0.34 & 0.16 & & \\
Congressional Ideology & -0.53 & 0.17 & & \\
Party Transition & 0.05 & 0.12 & & \\
Party Unity (Polarization) & 1.53 & 0.73 & & \\
Overdispersion $(\theta)$ & 3.95 & 1.13 & & \\
& & & & \\
N & 273 & & & \\
AIC & 1800 & & & \\
- Log Likelihood & -890 & & & \\
\hline
\end{tabular}

a The table displays the results of a zero-inflated negative binomial model for counts of federal bureaucrats per month from January 1983 through September 2005.

b Vuong tests comparing the ZINB specification of to zero inflated poisson (ZIP) and negative binomial specifications yielded test statistics of $7.56(\mathrm{p}<.001)$ and $3.78(\mathrm{p}<.001)$ respectively suggesting that the ZINB specification is the best fit to the data. 


\begin{tabular}{|c|c|c|c|c|}
\hline & \multicolumn{2}{|c|}{ Count } & \multicolumn{2}{|c|}{ Zero Inflation } \\
\hline & Estimate $^{a}$ & St Error & Estimate & St Error \\
\hline Intercept & -0.33 & 0.48 & 2.01 & 0.58 \\
\hline Congressional Uncertainty & 2.38 & 0.28 & -12.62 & 2.30 \\
\hline Unified Republican & -0.36 & 0.15 & & \\
\hline Unified Democratic & -0.05 & 0.17 & & \\
\hline Congressional Ideology & -0.03 & 0.18 & & \\
\hline Party Transition & 0.26 & 0.13 & & \\
\hline Party Unity (Polarization) & 1.99 & 0.78 & & \\
\hline Overdispersion $(\theta)$ & 3.93 & 1.15 & & \\
\hline $\mathrm{N}$ & 273 & & & \\
\hline AIC & 1499 & & & \\
\hline - Log Likelihood ${ }^{\mathrm{b}}$ & -740 & & & \\
\hline
\end{tabular}

a The table displays the results of a zero-inflated negative binomial model (ZINB) for counts of federal bureaucrats per month from January 1983 through September 2005.

b Vuong tests comparing the ZINB specification of to zero inflated poisson (ZIP) and negative binomial specifications yielded test statistics of $4.71(\mathrm{p}<.001)$ and $3.67(\mathrm{p}<.001)$ respectively suggesting that the ZINB specification is the best fit to the data. 
Table A.3: Congressional Uncertainty and Career Bureaucrats in Business Regulation

\begin{tabular}{|c|c|c|c|c|}
\hline & \multicolumn{2}{|c|}{ Count } & \multicolumn{2}{|c|}{ Zero Inflation } \\
\hline & Estimate $^{a}$ & St Error & Estimate & St Error \\
\hline Intercept & -0.59 & 0.61 & 1.14 & 0.51 \\
\hline Congressional Uncertainty & 2.27 & 0.34 & -9.30 & 1.70 \\
\hline Unified Republican & -0.46 & 0.19 & & \\
\hline Unified Democratic & -0.25 & 0.21 & & \\
\hline Congressional Ideology & -0.23 & 0.22 & & \\
\hline Party Transition & -0.31 & 0.17 & & \\
\hline Party Unity (Polarization) & 1.99 & 0.98 & & \\
\hline Overdispersion $(\theta)$ & 2.68 & 1.2 & & \\
\hline $\mathrm{N}$ & 273 & & & \\
\hline $\mathrm{AIC}$ & 1379 & & & \\
\hline - Log Likelihood ${ }^{\mathrm{b}}$ & -679 & & & \\
\hline
\end{tabular}

a The table displays the results of a zero-inflated negative binomial (ZINB) model for counts of federal bureaucrats per month from January 1983 through September 2005.

b Vuong tests comparing the ZINB specification of to zero inflated poisson (ZIP) and negative binomial specifications yielded test statistics of $4.80(\mathrm{p}<.001)$ and $2.3(\mathrm{p}<.02)$ respectively suggesting that the ZINB specification is the best fit to the data. 